\title{
Increase in FLAIR Signal of the Fluid Within the Resection \\ Cavity as Early Recurrence Marker: Also Valid for Brain \\ Metastases?
}

\section{FLAIR-Signalanstieg der Flüssigkeit in der Resektionshöhle als früher Rezidivparameter: auch gültig für Hirnmetastasen?}

Authors

Stefanie Bette ${ }^{1}$, Jens Gempt ${ }^{2}$, Benedikt Wiestler ${ }^{1}$, Thomas Huber ${ }^{1}$, Hanno Specht ${ }^{3}$, Bernhard Meyer ${ }^{2}$, Claus Zimmer ${ }^{1}$, Jan S. Kirschke ${ }^{1}$, Tobias Boeckh-Behrens ${ }^{1}$

\section{Affiliations}

1 Department of Neuroradiology, Klinikum rechts der Isar, Technical University Munich, Germany

2 Department of Neurosurgery, Klinikum rechts der Isar, Technical University Munich, Germany

3 Department of Radiation Oncology, Klinikum rechts der Isar, Technical University Munich, Germany

Key words

tumor recurrence, FLAIR, brain metastases, signal increase

received 10.8.2016

accepted 4.10.2016

\section{Bibliography}

DOI http://dx.doi.org/10.1055/s-0042-119686

Published online: 2016 | Fortschr Röntgenstr 2017; 189: 63-70

(c) Georg Thieme Verlag KG Stuttgart · New York

ISSN 1438-9029

\section{Correspondence}

Dr. Stefanie Bette

Department of Neuroradiology, Klinikum rechts der Isar, Technical

University Munich

Ismaningerstr. 22

81675 München

Germany

Tel.: ++ 49/89/41404651

stefanie.bette@tum.de

\section{ZUSAMMENFASSUNG}

Ziel Ein FLAIR Signalanstieg der Flüssigkeit in der Resektionshöhle wurde als spezifisches und frühes Zeichen für einen Tumorprogress/ ein Tumorrezidiv beschrieben. Ziel dieser Studie war es, die Wertigkeit dieses Zeichens bei zuvor operierten Hirnmetastasen zu untersuchen. Material und Methoden 209 Fälle mit zuvor operierten zerebralen Metastasen wurden retrospektiv untersucht, 41 Fälle mit mindestens zwei MRT-Verlaufskontrollen wurden in die Studie eingeschlossen. Die FLAIR-Signalintensität wurde sowohl qualitativ als auch quantitativ in der MRT mit einem Tumorrezidiv/in der letzten MRT als auch in der vorherigen MRT erfasst.
Ergebnisse 3 von 6 Fällen mit einem lokalen Tumorrezidiv zeigten einen FLAIR-Signalanstieg (Sensitivität 50,0\%, Spezifität 100,0\%). In einem Fall wurde dieses Zeichen sogar ca. 3 Monate vor Diagnose des Tumorrezidivs beobachtet. Die Spezifität für ein Tumorrezidiv (lokal und distant) lag ebenfalls bei $100,0 \%$ mit einer jedoch niedrigeren Sensitivität (13,0\%). Die quantitative Analyse zeigte signifikante Unterschiede der Signalintensität in der Resektionshöhle bei Patienten mit und ohne lokales Tumorrezidiv, ebenso für die Änderung der Signalintensität.

Schlussfolgerung Ein FLAIR-Signalanstieg der Flüssigkeit in der Resektionshöhle könnte auch bei zuvor operierten Hirnmetastasen ein spezifisches und frühes Zeichen für einen Tumorprogress / ein Tumorrezidiv sein.

\section{Kernaussagen}

- Ein FLAIR-Signalanstieg der Flüssigkeit in der Resektionshöhle wird nicht nur bei Gliomen, sondern auch bei Hirnmetastasen beobachtet

- Die Pathophysiologie dieses Zeichens könnte auf einen proliferativen Prozess zurückzuführen sein

\section{ABSTRACT}

Purpose Increase in FLAIR signal of the fluid within the resection cavity is described as a highly specific and early sign for tumor recurrence in gliomas. The aim of this study was to assess the prognostic value of FLAIR signal increase in partially or completely resected brain metastases.

Materials and Methods 209 cases of surgery for brain metastases were assessed. 41 cases with at least two follow-up MRIs were retrospectively included in this study. Quantitative and qualitative assessment of the FLAIR signal intensity of the fluid within the resection cavity was performed in the MRI examination at recurrent disease/ last contact and in the previous MRI examination.

Results 3 of 6 cases with local tumor recurrence showed a FLAIR signal increase (sensitivity $50.0 \%$, specificity $100.0 \%$ ). In one case, this sign was observed even about 3 months before tumor recurrence. The specificity of FLAIR signal increase for overall tumor recurrence (local and distant) was also $100.0 \%$, but with a lower sensitivity of $13.0 \%$. Quantitative analysis showed significant differences for signal intensity of the resection cavity as well as for the change of signal intensity of the resection cavity in cases with or without local tumor recurrence. Conclusion An increase in FLAIR signal of the fluid within the resection cavity might be a highly specific and early sign of local tumor recurrence/tumor progression also for brain metastases. 
Key points:

- An increase in FLAIR signal intensity of the fluid within the resection cavity is also observed in previously resected brain metastases.

- The pathophysiology of this sign might be due to a cell-proliferative process.

\section{Citation Format}

- Bette S, Gempt J, Wiestler B et al. Increase of the FLAIR Signal of the Fluid within the Resection Cavity as Early Recurrence Marker: Also Valid for Brain Metastases?. Fortschr Röntgenstr 2017; 189: 63-70

\section{Introduction}

Brain metastases are the most common malignant brain tumors in adults. Especially breast cancer, lung cancer, melanoma and renal cell cancer are known to develop brain metastases [1, 2]. According to current guidelines, surgery is recommended for symptomatic and accessible brain metastases followed by whole-brain irradiation or stereotactic irradiation [3-6]. As surgery is a safe treatment according to a recent study, some risk factors such as location in an eloquent region or preoperative radiotherapy that may increase the risk of postoperative neurological deficits have to be considered preoperatively [7].

Magnetic resonance imaging (MRI) is used for surveillance of therapy and detection of tumor progression or tumor recurrence. Early detection of tumor recurrence/progression is important to adapt therapy regimes in a timely manner. Recent studies showed a signal increase in T2-weighted fluid attenuated inversion recovery (FLAIR) sequences of the fluid within the resection cavity as a specific and early sign for tumor recurrence/tumor progression in glioma patients [8-10]. To our knowledge, this has not yet been assessed for brain metastases.

Analogously to a previous study [8], the aim of this study was to analyze the prognostic value of a FLAIR signal increase in fluid within the resection cavity for tumor recurrence/tumor progression in patients with previously resected brain metastases.

\section{Methods}

\section{Patient population}

The local ethics committee (5626/12) approved this non-interventional single-center study. The study was performed in accordance with the ethical standards of the 1964 Declaration of Helsinki and its later amendments [11].

Data analysis was performed by a neuroradiologist (SB, 6 years of experience) analogously to the previous study [8]. Retrospective analysis of 204 patients with 209 consecutive surgeries for brain metastases (recurrent or primary disease) between December 2008 and December 2015 was performed. Patients with an early postoperative MRI examination and at least two follow-up MRI examinations were included. Patients with a shrunken resection cavity (smaller than the intended size for measurement of regions of interest (ROIs)) $(n=46)$, missing follow-up MRI scan $(n=111)$, infection in the resection cavity $(n=6)$, missing FLAIR images $(n=3)$, solid tumor in the resection cavity $(n=1)$ or blurred images $(n=1)$ were excluded. Therefore, 35 patients with 41 surgeries were included in the analysis. In two patients two different resection cavities (right and left hemisphere) and in one patient three different resection cavities (both hemispheres) were analyzed and assessed as two/three different cases. Surgery of brain metastases was performed with the aim of the maximum resection of the contrast-enhancing part of the tumor while sparing motor and language function. The extent of resection was assessed in the early postoperative MRI examination and defined as: complete resection (total resection of the contrast-enhancing part of the tumor), incomplete resection (residual contrast-enhancing tumor at the resection cavity) or complete resection in the resection cavity but residual distant metastases. The date of FLAIR signal intensity change, date of MRI examination at recurrent disease/follow-up, date of previous MRI, and date of surgery and previous radiotherapy were recorded. Tumor progression/tumor recurrence was defined according to the RANO criteria for brain metastases and in an interdisciplinary consensus (neuroradiology, neurosurgery, radiation oncology, nuclear medicine) [12]. The date of change in further treatment (e. g. surgery, radiotherapy) was defined as the date of tumor recurrence/tumor progression. Advanced imaging methods such as perfusion or (O-(2[18-F]-Fluorethyl)-L-Tyrosin-Positron Emission Tomography [FET-PET]) were used for the diagnosis of tumor progression or tumor recurrence in unclear cases. Tumor recurrence/tumor progression was classified as local (at the site of previous surgery) or distant (distant to the site of previous surgery) tumor recurrence/ progression.

\section{Magnetic resonance imaging}

MRI scans were performed similarly to the previous study [8] either on a Philips Achieva $(n=12)$, Ingenia $(n=4)$ or Gyroscan $(n=3)$ (Philips Medical Systems, The Netherlands B.V.) or on a Siemens Verio $(n=12)$, Avanto $(n=6)$, Skyra $(n=1)$ or Symphony $(n=1)$, (Siemens Healthcare, Erlangen, Germany). On the Philips Achieva the following sequences were acquired: axial T2-weighted (w) FLAIR images (acquisition time 3:00 min, TR/TE of 12 000/ $140 \mathrm{~ms}, 0.45 \times 0.45 \times 4 \mathrm{~mm}$ spatial resolution) or T2w $3 \mathrm{D}$ FLAIR images (acquisition time 4:52 min, TR/TE 4800/278 ms, $1.04 \times 1.04 \times 1.12 \mathrm{~mm}$ spatial resolution) as well as axial T1w fast field echo (FFE) images pre and post gadolinium T1w images (acquisition time: 2:53 min, TR/TE 530/10 ms, $0 \times 45 \times 0.45 \times 4 \mathrm{~mm}$ spatial resolution) or pre and post gadolinium MPRage images (acquisition time 5:55 min, TR/TE 9/4 ms, $1 \mathrm{~mm}^{3}$ isotropic spatial resolution). On the Siemens Verio axial T2w FLAIR images (acquisition time 3:44 min, TR/TE $8560 / 136 \mathrm{~ms}, 0.8 \times 0.7 \times 4 \mathrm{~mm}$ spatial resolution) or T2w $3 \mathrm{D}$ FLAIR (acquisition time 5:52 min, TR/TE $5000 / 395 \mathrm{~ms}, 1 \mathrm{~mm}^{3}$ isotropic spatial resolution) and axial T1w images pre and post gadolinium ( $\mathrm{T} 1$ inversion recovery, time of inversion $860 \mathrm{~ms}$, acquisition time 4:02 min, TR/TE 2000/9 ms, $0.9 \times 0.7 \times 4 \mathrm{~mm}$ spatial resolution) or MPRage (acquisition time 4:18 min, TR/TE $1900 / 2.45 \mathrm{~ms}, 1.1 \times 1.1 \times 1 \mathrm{~mm}$ spatial resolution) were assessed. The contrast agent Magnograf ${ }^{\circledR}$ or Magne- 
vist ${ }^{\circledR}$ was administered intravenously $(0.2 \mathrm{ml} / \mathrm{kg}, 0.5-1 \mathrm{ml} / \mathrm{sec})$ using an MR-compatible contrast medium injection system (Spectris Solaris EP, Siemens Medical, Erlangen, Germany). Axial or coronal T2w FLAIR images were acquired in 26 cases, and 3Dw FLAIR images in 15 cases.

\section{Image analysis}

Image analysis was also performed by a neuroradiologist (SB, 6 years of experience) as previously described, who was not blinded to the patient data $[8,10]$. A second rater (TBB, 10 years of experience) also assessed the MR images while blinded to the clinical data. Interrater reliability for qualitative analysis was assessed using Cohen's kappa. The signal intensity in FLAIR images (classified as: normal signal intensity compared to cerebrospinal fluid (CSF) or elevated signal intensity) was assessed at the date of recurrent disease/last MRI. For qualitative analysis the signal intensity was compared to the previous MRI scan and classified as increase/decrease or no change. Analysis was not performed in the early postoperative MRI examination ( $<72$ hours after surgery) to avoid bias due to postoperative hemorrhage. The connection of the resection cavity to CSF was classified as visible open connection/no visible open connection. The date of signal intensity change (increase or decrease) was recorded.

Quantitative analysis was also performed as previously described $[8,10]$. Signal intensity was assessed in the MRI examination with recurrent disease/last contact and in the previous MRI examination via regions of interest (ROIs) with a size of 5 $10 \mathrm{~mm}$ that were drawn in the resection cavity (1), extracranially (2) to avoid background noise and in the CSF to avoid bias due to measurement on different scanners (3) ( $\triangleright$ Fig. 1). ROI ratios of $1 /$ 2 and $1 / 3$ were calculated. Differences in signal intensity were calculated for ROls measured in the resection cavity (ROI 1) as well as for $\mathrm{ROI}$ ratios $1 / 2$ and $1 / 3$ and then again classified as increase/decrease or no change.

\section{Statistical analysis}

Statistical analysis including descriptive data analysis was performed using IBM SPSS Statistics version 23.0 (SPSS Inc., IBM Corp., Armonk, NY, USA). Normally distributed data are shown as mean (+/- standard deviation). Non-normally distributed data are shown as median (interquartile range (IR)). For comparison between two independent groups, the Mann-Whitney U Test was performed. Specificity and sensitivity were calculated. A pvalue $<.05$ was defined as significant.

\section{Results}

\section{Patient and tumor characteristics ( $\triangleright$ Table 1 )}

41 cases (20 male, 21 female, mean age at date of surgery 57y) with the diagnosis of a brain metastasis and neurosurgical resection were retrospectively included in this study. Complete tumor resection was achieved in 24/41 cases. In 8/41 cases local complete tumor resection was achieved, but other metastases were present. 36/41 patients received radiotherapy after surgery during follow-up. Histopathological analysis revealed brain metastases of lung cancer $(n=5)$, breast cancer $(n=13)$, melanoma

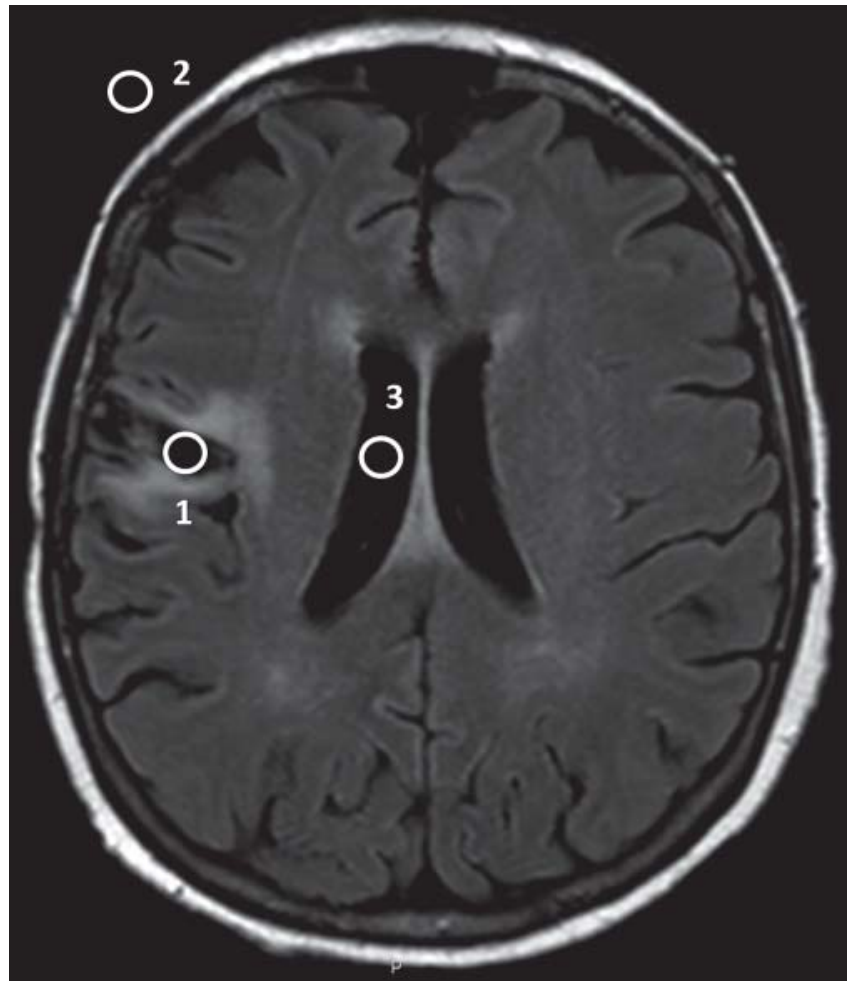

- Fig. 1 Quantitative analysis of FLAIR signal intensity using regions of interest (ROIs). Resection cavity (1), extracranial (2) and cerebrospinal fluid (3).

- Abb. 1 Quantitative Analyse der FLAIR-Signalintensität anhand Regions of Interest (ROIs). Resektionshöhle (1), extrakraniell (2), Liquor (3).

$(n=2)$, gastrointestinal cancer $(n=6)$, renal cell/urothelial cancer $(n=6)$, sarcoma $(n=2)$, germ cell cancer $(n=3)$ and other cancers $(n=4)$. Table 1 lists the histological entities of the brain metastases.

23/41 cases presented with recurrent disease during followup. 6 cases showed local tumor recurrence. 17 cases showed distant tumor recurrence only. The median time of the observation period was 462 days (IR 259 -994days). Recurrent disease was proven by MR imaging according to the RANO criteria in 16 cases or by additional advanced imaging methods (including FET-PET) in 1 case. 5 patients received further surgery for recurrent disease, and tumor cells were found in the CSF in 1 patient. Local recurrent disease was proven histopathologically in 2/6 cases by another surgery, in one case by proof of tumor cells in the CSF, in one case by advanced imaging methods (FET-PET) and in two cases by progression of the residual tumor.

\section{Qualitative analysis ( Table 2, 3, > Fig. 2, 3)}

Interrater reliability revealed excellent agreement between the two raters (Cohen's kappa $=1$ ). A change of FLAIR signal intensity of the fluid within the resection cavity was observed in 10/41 $(24.4 \%)$ cases. An increase in FLAIR signal intensity was recorded in $3 / 41$ ( $7.3 \%$ ) cases, while a decrease was recorded in $7 / 41$ (17.1\%) cases. $3 / 23(13.0 \%)$ cases with recurrent (local and distant) disease showed a signal increase, whereas $3 / 6$ (50.0\%) cases 
- Table 1 Baseline Patient and Tumor Characteristics.

\begin{tabular}{|l|l|}
\hline age & $57 y(+/-14 y)$ \\
\hline sex, female & $21 / 41(51.2 \%)$ \\
\hline histopathology & \\
\hline lung cancer & $5 / 41(12.2 \%)$ \\
\hline breast cancer & $13 / 41(31.7 \%)$ \\
\hline melanoma & $2 / 41(4.9 \%)$ \\
\hline Gl cancer & $6 / 41(14.6 \%)$ \\
\hline renal cell/urothelial carcinoma & $6 / 41(14.6 \%)$ \\
\hline sarcoma & $2 / 41(4.9 \%)$ \\
\hline germ cell carcinoma & $3 / 41(7.3 \%)$ \\
\hline other cancers & $4 / 41(9.8 \%)$ \\
\hline - thymoma & $1 / 4$ \\
\hline - endometrial cancer & $1 / 4$ \\
\hline - CNS lymphoma & $1 / 4$ \\
\hline - CUP & $1 / 4$ \\
\hline recurrent disease during FU & $23 / 41(56.1 \%)$ \\
\hline - local recurrence & $6 / 41(14.6 \%)$ \\
\hline - distant recurrence only & $17 / 41(41.5 \%)$ \\
\hline previous radiotherapy & $36 / 41(87.8 \%)$ \\
\hline extent of resection & \\
\hline - complete resection & $24 / 41(58.5 \%)$ \\
\hline - local incomplete resection & $9 / 41(22.0 \%)$ \\
\hline - complete resection, other metastases & $8 / 41(19.5 \%)$ \\
\hline connection resection cavity to CSF & $6 / 41(14.6 \%)$ \\
\hline & \\
\hline
\end{tabular}

Normally distributed variables shown as mean $+/$ - standard deviation: GI: gastrointestinal; CNS: central nervous system; CUP: cancer of unknown primary; FU: follow-up; CSF: cerebrospinal fluid.

with local recurrent disease showed a signal increase (gastrointestinal cancer $(n=1)$, germ cell cancer $(n=1)$, sarcoma $(n=1))$. All patients with an increase in signal intensity of the resection cavity showed local tumor recurrence resulting in a specificity of $100.0 \%$ (95\% confidence interval $(\mathrm{Cl}) 90.0-100.0 \%$ ) and a sensitivity of $13.0 \%$ ( $95 \% \mathrm{Cl} 2.8-33.6 \%$ ) of FLAIR signal increase for tumor recurrence and a specificity of $100.0 \%(95 \% \mathrm{Cl} 90.0-100.0 \%)$ and a sensitivity of $50.0 \%(95 \% \mathrm{Cl} 11.8-88.2 \%)$ for local tumor recurrence. None of the patients with distant tumor recurrence only showed a signal increase in the resection cavity. 2 cases showed a change in signal intensity at the date of recurrent disease. In one case a signal intensity increase was observed 122 days before the date of recurrent disease. All three cases with an increase in signal intensity of the fluid within the resection cavity showed no connection to the cerebrospinal fluid and had undergone previous radiotherapy. 2 of the 3 cases with a signal intensity increase had previous incomplete tumor resection, and 1 case had complete tumor resection.
- Table 2 Qualitative Assessment of FLAIR Signal Intensity.

\begin{tabular}{|l|l|}
\hline change of signal intensity & $10 / 41(24.4 \%)$ \\
\hline increase & $3 / 10(30.0 \%)$ \\
\hline decrease & $7 / 10(70.0 \%)$ \\
\hline \begin{tabular}{l} 
recurrent disease \\
\hline - increase/recurrent disease
\end{tabular} & $3 / 23$ \\
\hline - increase/no recurrent & $0 / 23$ \\
\hline $\begin{array}{l}\text { disease } \\
\text { - specificity of signal } \\
\text { increase }\end{array}$ & $100.0 \%(95 \% \mathrm{Cl} 90.0-100.0 \%)$ \\
\hline - sensitivity of signal increase & $13.0 \%(95 \% \mathrm{Cl} 2.8-33.6 \%)$ \\
\hline $\begin{array}{l}\text { local recurrence } \\
\text { - increase/local recurrence }\end{array}$ & $3 / 6$ \\
\hline - increase/no local \\
recurrence
\end{tabular}

- Table 3 Quantitative Assessment of FLAIR Signal Intensity. signal intensity of resection cavity

\begin{tabular}{|l|l|}
\hline - recurrent disease & $41.0(24.0-224.0)$ \\
\hline - no recurrent disease & $53.5(29.8-171.8)$ \\
\hline - local recurrence & $292.0(112.3-646.5)^{1}$ \\
\hline - no local recurrence & $38.0(24.0-135.0)^{1}$ \\
\hline
\end{tabular}

change of signal intensity of resection cavity

\begin{tabular}{l|l}
\hline - recurrent disease & $8.0(-43.7-56.0)$ \\
\hline
\end{tabular}

- no recurrent disease $\quad-13.0(287.5-16.8)$

\begin{tabular}{l|l} 
specificity & $61.1 \%(95 \% \mathrm{Cl} 35.8-82.7 \%)$ \\
\hline
\end{tabular}

\begin{tabular}{l|l} 
sensitivity & $56.5 \%(95 \% \mathrm{Cl} 34.5-76.8 \%)$
\end{tabular}

change of signal intensity of resection cavity

\begin{tabular}{|l|l|}
\hline - local recurrence & $76.5(-12.5-428.0)^{1}$ \\
\hline - no local recurrence & $-12.0(-87.0-16.0)^{1}$ \\
\hline specificity & $57.1 \%(95 \% \mathrm{Cl} 39.4-73.7 \%)$ \\
\hline sensitivity & $83.3 \%(95 \% \mathrm{Cl} 35.9-99.6 \%)$ \\
\hline
\end{tabular}

Non-normally distributed data shown as median (interquartile range); $\mathrm{Cl}$ : confidence interval.

$1 \mathrm{P}<0.05$.

\section{Quantitative analysis ( $\triangleright$ Table 3)}

Significantly higher values of signal intensity in the resection cavity were observed in cases with local recurrent disease than in cases without recurrent disease (292.0 [112.3 - 646.5] vs. 38.0 [24.0 -135.0$], P=0.004$ ) and for the change in signal intensity in 

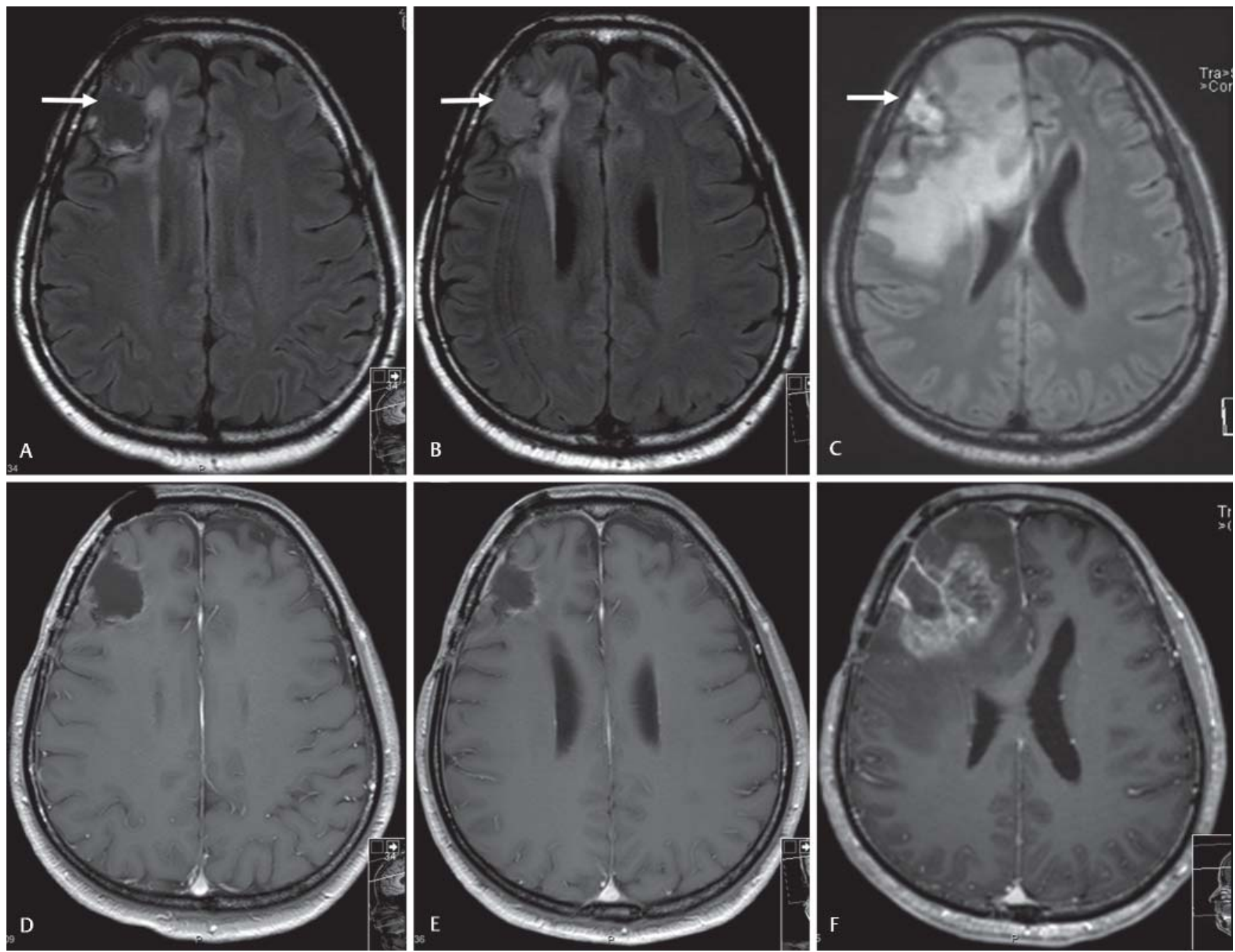

- Fig. 2 Case of a patient with previous resection of an intracranial sarcoma metastasis. The first column shows FLAIR A and post contrast T1w D images during follow-up. The second column shows FLAIR signal increase $\mathbf{B}$ in the resection cavity, but no contrast enhancement $\mathbf{E}$. The third column shows follow-up MRI 122 days later that reveals a further FLAIR signal intensity increase $\mathbf{C}$ and also contrast enhancement surrounding the resection cavity. Diagnosis of recurrent disease was confirmed histopathologically.

- Abb. 2 Fall eines Patienten mit zuvor resezierter zerebraler Sarkommetastase. Die erste Spalte zeigt FLAIR A und T1-gewichtete Aufnahmen nach Kontrastmittel D. Die zweite Spalte zeigt einen FLAIR-Signalanstieg der Flüssigkeit in der Resektionshöhle B, aber keine Kontrastmittelanreicherung E. Die dritte Spalte zeigt ein Verlaufs-MRT 122 Tage später, das einen weiteren FLAIR-Signalanstieg zeigt C und auch eine Kontrastmittelanreicherung $\mathbf{F}$, die Rezidivdiagnose wurde histologisch gesichert.

the resection cavity $(76.5[-12.5-428.0]$ vs. $-12.0[-87.0-16.0]$, $\mathrm{P}=0.031)(\vee$ Fig. 4). No differences were observed for signal intensity values in the resection cavity in cases with or without overall tumor recurrence $(41.0$ [24.0 - 224.0] vs. 53.5 [29.8-171.8], $\mathrm{P}=0.958$ ). Similar results are shown for the ratios ROI1/2 and ROI1/3, > Table 4 (online).

Quantitative assessment of FLAIR signal increase showed a sensitivity and specificity of $56.5 \%(95 \% \mathrm{Cl} 34.5-76.8 \%)$ and $61.1 \%$ ( $95 \% \mathrm{Cl} 35.8-82.7 \%$ ), respectively, for tumor recurrence and a sensitivity and specificity of $83.3 \%(95 \% \mathrm{Cl} 35.9-99.6 \%)$ and $57.1 \%$ (95\% Cl 39.4- $73.7 \%$ ), respectively, for local tumor recurrence.

\section{Discussion}

An increase in FLAIR signal intensity of the fluid within the resection cavity might be an early and highly specific sign of local tumor recurrence for patients with brain metastases. Accordingly, this sign is not glioma-specific, but specific for cell-proliferative processes revealing more information about the pathophysiology of FLAIR signal increase.

Previous studies showed that an increase in FLAIR signal of the fluid within the resection cavity occurs in partially and completely resected glioma and is a specific sign for tumor recurrence and tumor progression [8-10]. However, the pathophysiology of this sign still remains unclear. The previous studies postulated that FLAIR signal increase might occur due to an encapsulation of the resection cavity by tumor cells leading to higher protein concentration. This hypothesis is also confirmed by the fact that this sign 


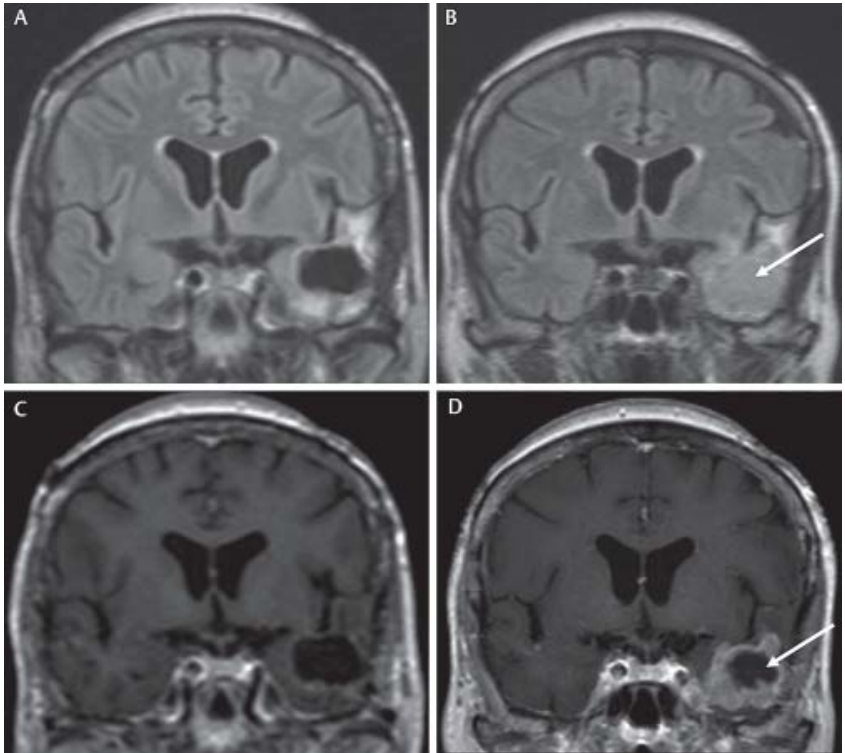

- Fig. 3 Case of a patient with previous incomplete resection of ovarial cancer brain metastasis. FLAIR images during follow-up B show an increase in signal intensity in the resection cavity. Progressive contrast enhancement was observed surrounding the resection cavity D.

- Abb. 3 Fall einer Patientin mit einer zuvor inkomplett resezierten Hirnmetastase eines Ovarial-Karzinoms. Die FLAIR-Aufnahmen im Verlauf B zeigen einen Signalanstieg der Flüssigkeit in der Resektionshöhle, zudem zeigt sich eine progrediente Kontrastmittelanreicherung um die Resektionshöhle $\mathbf{D}$.

mainly occurs in cases without an open connection of the resection cavity to the CSF. In these cases exchange of CSF is not possible, leading to higher protein concentration and hindering washout of the protein $[8,10]$. Also in this study a FLAIR signal increase was only observed in cases without an open connection to the CSF, thus supporting this hypothesis.

A FLAIR signal increase is observed as a specific sign for local tumor recurrence, but not for distant tumor recurrence in brain metastases as was expected according to the potential pathophysiology. Moreover, this strengthens the hypothesis of the potential described pathomechanism. As a FLAIR signal increase is also observed in brain metastases and not only in gliomas, the conclusion can be drawn that this sign is not glioma-specific, but also occurs in other cell-proliferative diseases. This fact also supports the hypothesis that encapsulation of the resection cavity by tumor cells is the possible pathophysiology of the signal increase. However, this is still a theory and studies with analysis of the fluid composition will have to be performed to investigate the exact pathomechanisms of the signal increase.

The previous study showed that a FLAIR signal increase can occur in partially and completely resected and in irradiated and only rarely in non-irradiated gliomas [8]. In this study a signal increase was observed in both completely and partially resected brain metastases, but only in irradiated metastases. However, as a FLAIR signal increase was only observed in two completely and one partially resected as well as in three irradiated brain metastases in this study, the validity of this sign for subgroups is too low. Further
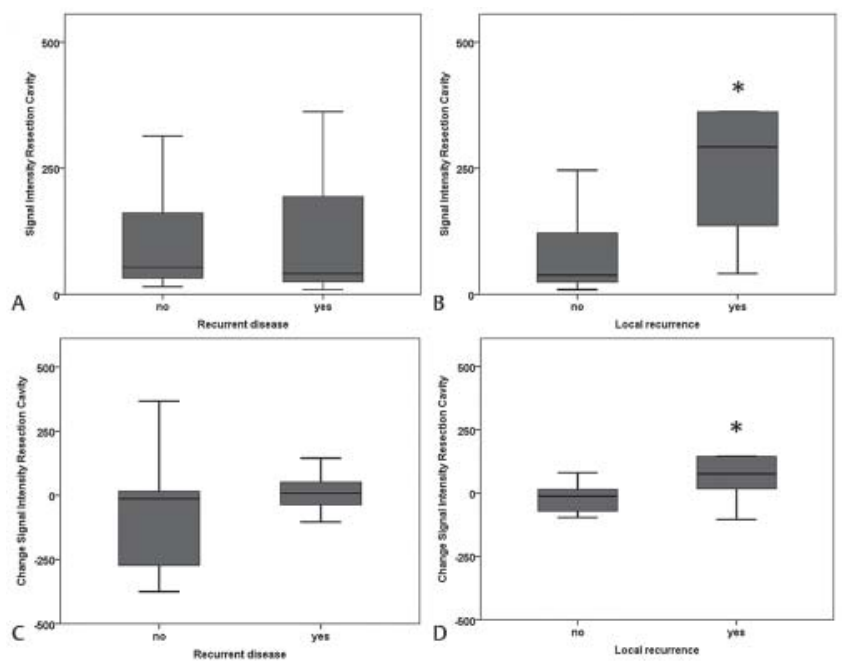

- Fig.4 Box plots for signal intensity values in the resection cavity $A$ and for the change of signal intensity in the resection cavity $\mathbf{C}$ in cases with and without recurrent disease and in cases with or without local tumor recurrence $\mathbf{B}, \mathbf{D}$ respectively. ${ }^{*} \mathrm{P}<0.05$.

- Abb. 4 Kastengrafik für die Signalintensität in der Resektionshöhle $\mathbf{A}$ und für die Änderung der Signalintensität in der Resektionshöhle $\mathbf{C}$ in Fällen mit oder ohne Tumorrezidiv und in Fällen mit oder ohne lokales Tumorrezidiv B, D. ${ }^{*} \mathrm{P}<0.05$.

studies with larger patient cohorts will have to be performed. Furthermore, the delineation between complete and partial tumor resection remains challenging in malignant brain tumors - both in gliomas and in brain metastases - as the exact borders of the tumor are hard to define $[13,14]$.

Hemorrhage as well as infarction with a subsequently disrupted brain barrier are described as showing a FLAIR signal increase and may represent a pitfall in the application of this sign for tumor recurrence/tumor progression [15, 16]. Hemorrhage as a confounding factor of FLAIR hyperintensity was discussed in the previous studies $[8,10]$. As bleeding is a rare complication in glioma [17, 18 ], it is observed more often in brain metastases, especially in brain metastases of melanoma or renal cancer [1]. In our study bleeding was mainly observed in the early postoperative MRI examination ( $<72$ hours after surgery) and not during follow-up. Therefore, only cases with at least two follow-up MRI scans after the early postoperative MRI scan were included in order to avoid this bias. To avoid misinterpretation due to bleeding in the resection cavity, T1-weighted images without contrast agent are important for differentiation and are also routinely used in brain tumor imaging [19]. Moreover, postoperative infarction is observed after surgery of brain metastases and may cause a bias of the FLAIR signal increase [20]. However, vasogenic edema due to infarction is observed mainly in the first days after surgery and these images were excluded from analysis.

In addition to hemorrhage and infarction, infection might present another pitfall in the evaluation of the FLAIR signal intensity of the resection cavity as discussed previously [8]. Intracranial infection is known to show a higher protein concentration and subsequently a higher FLAIR signal intensity [21]. In our study patients with infection in the resection cavity were excluded from analysis 
to avoid this bias. However, in the clinical routine diffusionweighted imaging, which is routinely used in brain tumor imaging, can help to differentiate a FLAIR signal increase due to infection from a FLAIR signal increase due to tumor progression/tumor recurrence [22, 23].

Comparing this method to other advanced imaging methods such as perfusion-weighted imaging and PET imaging, the sensitivity of $50.0 \%$ is low, thus making this sign unsuitable for screening [24-29]. However, the high specificity is of significant importance in the clinical routine. FLAIR images are included in the standard imaging protocol of brain tumors. No other imaging methods have to be used.

The main limitations of this study are its retrospective design and the low patient number, especially the low number of patients with a FLAIR signal increase and local tumor recurrence. However, in this study we assessed 204 patients. Due to missing follow-up or shrinking of the resection cavity, many cases could not be included for further analysis. This might be explained by the poor prognosis of patients with brain metastases as well as by early tumor recurrence/tumor progression despite therapy in many cases (depending on the histopathological subtype) [5]. Also the number of cases of local tumor recurrence especially after local radiotherapy to the resection bed is low compared to the risk of distant tumor recurrence/progression [30]. Furthermore, a separate analysis for different histopathological subtypes of brain metastases might be useful to estimate the value of this sign for each primary tumor. However, due to the low number of patients developing this sign $(n=3)$, this calculation is not possible and might be a subject for further studies.

Another limitation is the analysis of data from different MR scanners and different sequences which might introduce an unavoidable bias. To reduce this bias, the ratio of the FLAIR signal intensity in the resection cavity compared to the CSF was calculated as previously described and showed similar results [10]. However, to solve this problem, further studies with images from a single MR scanner with the same FLAIR sequence should be performed.

Another limitation might arise due to the sometimes quite difficult differentiation between tumor progression and pseudoprogression in brain metastases [28, 31, 32]. For gliomas, PET and perfusion imaging are important for differentiation. For brain metastases, the data are limited, and progression is defined according to the RANO criteria for brain metastases [12, 24, 26, 27, 33, 34]. In this study, recurrent tumor was proven histopathologically in 3 of 6 cases with local recurrence. The other 3 cases were either proven by advanced imaging methods (PET) or progressive residual tumor.

\section{CLINICAL RELEVANCE OF THIS STUDY}

- An increase in FLAIR signal intensity of the fluid within the resection cavity might be a highly specific and early sign for local tumor recurrence/progression also for brain metastases, suggesting that this sign is not glioma-specific, but specific for cell-proliferative processes.

- As FLAIR images are included in the standard imaging protocol in brain tumor imaging, this sign might help in the diagnosis of tumor recurrence or tumor progression in completely or partially resected brain metastases.

- Studies with larger patient cohorts should be performed to confirm the results of this study.

$\begin{array}{ll}\text { ABBREVIATIONS } \\ \text { FLAIR } & \text { fluid attenuated inversion recovery } \\ \text { MPRage } & \text { magnetization prepared rapid gradient echo } \\ \text { MRI } & \text { magnetic resonance imaging } \\ \text { IR } & \text { interquartile range } \\ \text { SI } & \text { signal intensity } \\ \text { NPV } & \text { negative predictive value } \\ \text { PPV } & \text { positive predictive value } \\ \text { CSF } & \text { cerebrospinal fluid } \\ \text { CI } & \text { confidence interval }\end{array}$

\section{Acknowledgments}

We thank Birgit Waschulzik from the Department of Statistics and Epidemiology, Technische Universität München, for statistical support.

\section{Conflict of interest}

SB, JG, TH and BM work as consultants for Brainlab AG (Feldkirchen, Germany). CZ has served on scientific advisory boards for Philips and Bayer Schering; serves as co-editor on the Advisory Board of Clinical Neuroradiology; has received speaker honoraria from Bayer-Schering and Philips and has received research support and investigator fees for clinical studies from Biogen Idec, Quintiles, MSD Sharp \& Dome, Boehringer Ingelheim, Inventive Health Clinical UK Ltd., Advance Cor, Brainsgate, Pfizer, BayerSchering, Novartis, Roche, Servier, Penumbra, WCT GmbH, Syngis, SSS Internartional Clinical Research, PPD Germany GmbH, Worldwide Clinical Trials Ltd., Phenox, Covidien, Actelion, Medivation, Medtronic, Harrison Clinical Research, Concentric, Penumbra, Pharmtrace, Reverse Medical Corp., Premier Research Germany Ltd., Surpass Medical Ltd. and GlaxoSmithKline. All named potential conflicts of interest are unrelated to this study. 


\section{References}

[1] Fink KR, Fink JR. Imaging of brain metastases. Surgical neurology international 2013; 4: S209-S219

[2] Soffietti R, Cornu P, Delattre JY et al. EFNS Guidelines on diagnosis and treatment of brain metastases: report of an EFNS Task Force. European journal of neurology: the official journal of the European Federation of Neurological Societies 2006; 13: 674-681

[3] Bertolini F, Spallanzani A, Fontana A et al. Brain metastases: an overview. CNS oncology 2015; 4: 37-46

[4] Kalkanis SN, Kondziolka D, Gaspar LE et al. The role of surgical resection in the management of newly diagnosed brain metastases: a systematic review and evidence-based clinical practice guideline. J Neurooncol 2010; 96: 33-43

[5] Lin X, DeAngelis LM. Treatment of Brain Metastases. J Clin Oncol 2015; 33: $3475-3484$

[6] Lukas RV, Gabikian P, Garza M et al. Treatment of brain metastases. Oncology 2014; 87: $321-329$

[7] Obermueller T, Schaeffner M, Gerhardt J et al. Risks of postoperative paresis in motor eloquently and non-eloquently located brain metastases. BMC cancer 2014; 14: 21

[8] Bette S, Gempt J, Huber T et al. FLAIR signal increase of the fluid within the resection cavity after glioma surgery: Generally valid as early recurrence marker?. Journal of Neurosurgery 2016;; accepted. DOI: \#\#\#

[9] Ito-Yamashita T, Nakasu Y, Mitsuya K et al. Detection of tumor progression by signal intensity increase on fluid-attenuated inversion recovery magnetic resonance images in the resection cavity of high-grade gliomas. Neurologia medico-chirurgica 2013; 53: 496-500

[10] Winterstein M, Munter MW, Burkholder I et al. Partially resected gliomas: diagnostic performance of fluid-attenuated inversion recovery MR imaging for detection of progression. Radiology 2010; 254: 907-916

[11] General Assembly of the World Medical A. World Medical Association Declaration of Helsinki: ethical principles for medical research involving human subjects. The Journal of the American College of Dentists 2014; 81: $14-18$

[12] Lin NU, Lee EQ, Aoyama $\mathrm{H}$ et al. Response assessment criteria for brain metastases: proposal from the RANO group. Lancet Oncol 2015; 16: e270-e278

[13] Lu S, Ahn D, Johnson G et al. Diffusion-tensor MR imaging of intracranial neoplasia and associated peritumoral edema: introduction of the tumor infiltration index. Radiology 2004; 232: 221 - 228

[14] Siam L, Bleckmann A, Chaung HN et al. The metastatic infiltration at the metastasis/brain parenchyma-interface is very heterogeneous and has a significant impact on survival in a prospective study. Oncotarget 2015; 6: $29254-29267$

[15] Jha R, Battey TW, Pham L et al. Fluid-attenuated inversion recovery hyperintensity correlates with matrix metalloproteinase-9 level and hemorrhagic transformation in acute ischemic stroke. Stroke; a journal of cerebral circulation 2014; 45: 1040 - 1045

[16] Noguchi K, Ogawa T, Inugami A et al. Acute subarachnoid hemorrhage: MR imaging with fluid-attenuated inversion recovery pulse sequences. Radiology 1995; 196: 773-777

[17] Della Puppa A, Zustovich F, Gardiman M et al. Haemorrhagic presentation of low-grade glioma in adults. Acta neurochirurgica 2007; 149: 1151 - 1155; discussion 1155

[18] Licata B, Turazzi S. Bleeding cerebral neoplasms with symptomatic hematoma. J Neurosurg Sci 2003; 47: 201 -210; discussion 210
[19] Meyding-Lamade U, Forsting M, Albert F et al. Accelerated methaemoglobin formation: potential pitfall in early postoperative MRI. Neuroradiology 1993; 35: $178-180$

[20] Gempt J, Gerhardt ], Toth V et al. Postoperative ischemic changes following brain metastasis resection as measured by diffusion-weighted magnetic resonance imaging. Journal of Neurosurgery 2013; 119: $1395-1400$

[21] Mishra AM, Reddy S], Husain M et al. Comparison of the magnetization transfer ratio and fluid-attenuated inversion recovery imaging signal intensity in differentiation of various cystic intracranial mass lesions and its correlation with biological parameters. J Magn Reson Imaging 2006; 24: $52-56$

[22] Reiche W, Schuchardt V, Hagen T et al. Differential diagnosis of intracranial ring enhancing cystic mass lesions-role of diffusion-weighted imaging (DWI) and diffusion-tensor imaging (DTI). Clinical neurology and neurosurgery 2010; 112: $218-225$

[23] Xu XX, Li B, Yang HF et al. Can diffusion-weighted imaging be used to differentiate brain abscess from other ring-enhancing brain lesions? A meta-analysis. Clinical radiology 2014; 69: 909-915

[24] Galldiks N, DunkI V, Stoffels G et al. Diagnosis of pseudoprogression in patients with glioblastoma using O-(2-[18F]fluoroethyl)-L-tyrosine PET. Eur J Nucl Med Mol Imaging 2015; 42: 685-695

[25] Hatzoglou V, Yang T], Omuro A et al. A prospective trial of dynamic contrast-enhanced MRI perfusion and fluorine-18 FDG PET-CT in differentiating brain tumor progression from radiation injury after cranial irradiation. Neuro Oncol 2015. DOI: 10.1093/neuonc/nov301

[26] Suh CH, Kim HS, Choi Y] et al. Prediction of pseudoprogression in patients with glioblastomas using the initial and final area under the curves ratio derived from dynamic contrast-enhanced T1-weighted perfusion MR imaging. AJNR Am J Neuroradiol 2013; 34: 2278-2286

[27] Thomas AA, Arevalo-Perez J, Kaley T et al. Dynamic contrast enhanced T1 MRI perfusion differentiates pseudoprogression from recurrent glioblastoma. J Neurooncol 2015; 125: 183-190

[28] Zach L, Guez D, Last D et al. Delayed contrast extravasation MRI: a new paradigm in neuro-oncology. Neuro Oncol 2015; 17: 457-465

[29] Zakaria R, Das K, Bhojak M et al. The role of magnetic resonance imaging in the management of brain metastases: diagnosis to prognosis. Cancer imaging: the official publication of the International Cancer Imaging Society 2014; $14: 8$

[30] Hsieh J, Elson P, Otvos B et al. Tumor progression in patients receiving adjuvant whole-brain radiotherapy vs localized radiotherapy after surgical resection of brain metastases. Neurosurgery 2015; 76: 411-420

[31] Cohen JV, Alomari AK, Vortmeyer AO et al. Melanoma Brain Metastasis Pseudoprogression after Pembrolizumab Treatment. Cancer immunology research 2015. DOI: 10.1158/2326-6066.CIR-15-0160

[32] Zach L, Guez D, Last D et al. Delayed contrast extravasation MRI for depicting tumor and non-tumoral tissues in primary and metastatic brain tumors. PloS one 2012; 7: e52008

[33] Pyka TG], Ringel F, Hüttinger $S$ et al. Prediction of glioma recurrence using dynamic ${ }^{18}$ F-fluoroethyltyrosine PET. AJNR Am J Neuroradiol 2014; 35: $1924-1929$

[34] Wang S, Martinez-Lage M, Sakai Y et al. Differentiating Tumor Progression from Pseudoprogression in Patients with Glioblastomas Using Diffusion Tensor Imaging and Dynamic Susceptibility Contrast MRI. AJNR Am J Neuroradiol 2015. DOI: 10.3174/ajnr.A4474 